\title{
微細加工基板上の磁性膜の性質
}

\author{
小野 輝男, 新庄 輝也
}

京都大学化学研究所, $\overline{\mathbf{T}} 611$ 宇治市五ヶ庄.

\section{Magnetic Properties of Multilayers Prepared on Microstructured Substrates}

\author{
Teruo Ono and Teruya Shinjo \\ Institute for Chemical Research, Kyoto University, Uji 611.
}

Received July 14, 1995

\section{SYNOPSIS}

A new class of multilayers is fabricated on microstructured substrates. The Giant Magnetoresistance effect in a new geometry, CAP, (with current at an angle to the layer plane) was studied by using multilayers prepared on V-shaped groove structures with micron-scale. CAP-MR is larger than MR with current in the plane (CIP-MR). Moreover, MR value with current perpendicular to the plane (CPP-MR) is estimated by using observed CIP-MR and CAP-MR values. MR dependence in these geometries on temperature and spacer layer thickness was studied.

KEY WORDS

giant magnetoresistance, CPP-MR, metallic multilayer, microstructured substrate.

\section{1 緒 言}

磁性金属を含む金属人工格子は，垂值磁気異方性や巨大 磁気抵抗効果などの新奇な物性を示すため，基䃈と応用の 両面から精力的に研究されてきた，垂直磁気異方性を示す 人工格子は高密度記録媒体として，巨大磁気抵抗効果を示 す人工格子は高感度の磁気へッドとしての応用が期待され ている.

上述したような物性を示す人工格子は，これまで平嗗な 基板上に作成されてきた（Fig.1(a)）このような人工格 子は成長方向に原子層単位で制御された人工周期構造を持 ち、この原子層単位の構造が様々な興味ある人工格子特有 の物性を引き出している，一方，微細加工された基板上に 人工格子を作成することにより，人工格子に新たな構造を 付加することができる．それゆえ，微紐加工基板上の人工 格子は従来の人工格子では得られない新しい物性を示すこ
とが期待される。

半導体分野で培われた微細加工技術を用いることで， ミ クロン周期のV字形の唡をシリコン基板の表面に加工する ことができる. その概念図をFig.1(b)に示す。このような 基板に垂直方向から蒸着することによりFig.1(c)のような 形状の人工格子が得られる. 基板に対して斜㤎蒸着す るとFig.1(d)の様な形状の人工格子が，基板に対してすれ すれの方向から蒸着するとFig.1(e)のような人工格子の細 線が得られる，我々は，このような特異な形状をした人工 格子を利用し，磁性に対する形状異方性の効果や電気伝導 性に関して研究している. 今回は，Fig.1(c)の様な形状を した人工格子を用いた巨大磁気抵抗勃果の研究について報 告する.

巨大磁気抵抗効果は，1988年に $\mathrm{Fe} / \mathrm{Cr}$ 人工格子で発見さ

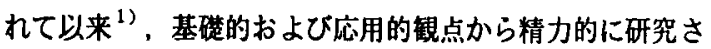


(a)

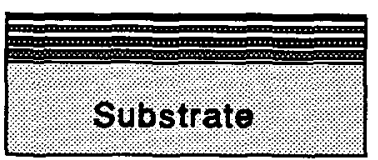

(b)

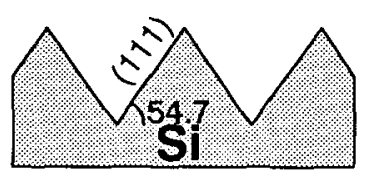

(c)

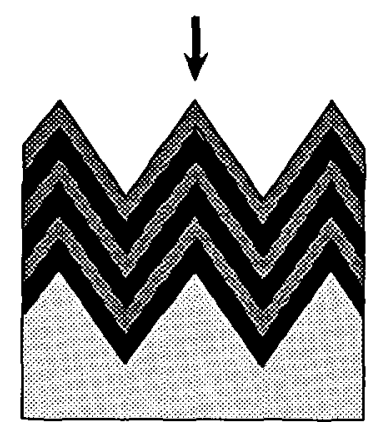

(d)

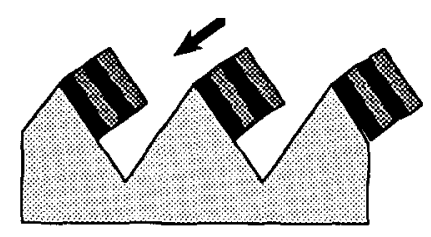

(e)

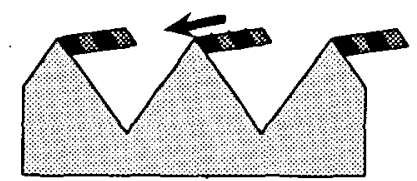

Fig.1 Schematic illustration of conventional multilayer (a), V-shaped substrate (b), multilayer which is prepared by depositing in a direction normal to the initial substrate plane (c), in a tilted direction (d), and in a glancing angle direction (e). Depositing direction are indicated by arrows.

れてきた．通常は，Fig.1(a)に示した形状の人工格子を用 いて, 人工格子膜面内に電流を流して磁気抵抗効果の測定 を行う、この様な測定の配置をCIP(current in the plane) 配置と呼んでいる，一方，人工格子膜面に垂直な電流によ る磁気抵抗測定は，CPP(current perpendicular to the plane)配置と呼ばれる.CPP-MRはCIP-MRより大きくな ることが理論的に示され ${ }^{2)}$ ，その検証が待たれた。しかし， (a)

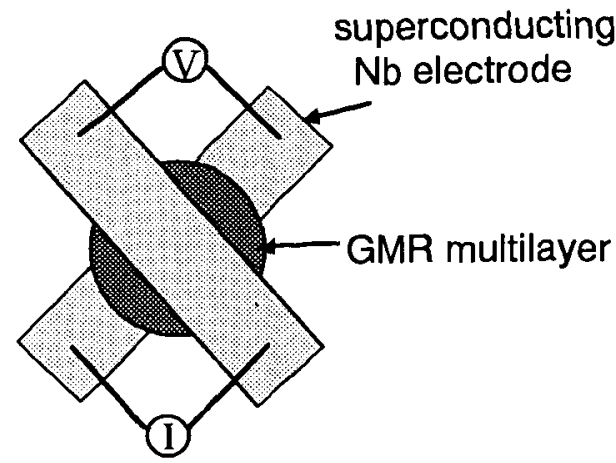

(b)

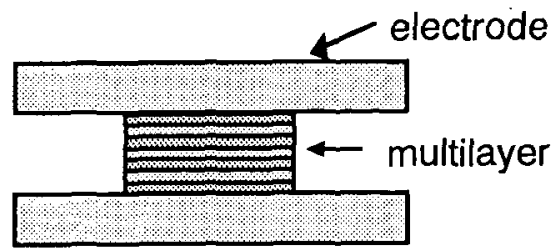

(c)

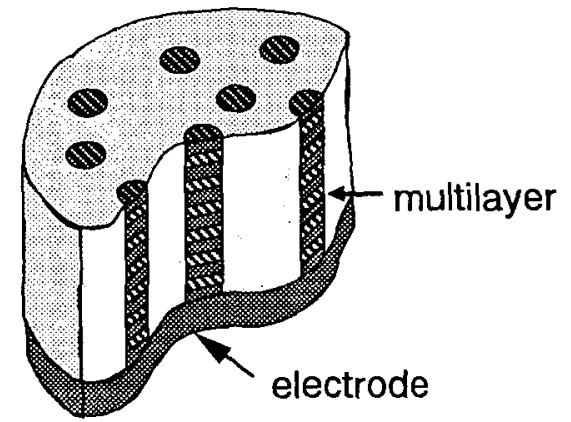

Fig.2 Schematic illustrations of CPP-MR measuring methods.

人工格子の膜厚は数千オングストローム程度であり，膜面 に垂直方向の抵抗は著しく小さくなってしまい測定は困難 を極める.この微小な抵抗の測定に初めて成功したのはミ シガン州立大学のグループである ${ }^{3)}$. 彼らは，Fig.2(a)に 示すように $\mathrm{Nb}$ の超伝導端子を用いることで端子抵抗を 減らし，微小な電压降下をSQUID素子を用いることで測 定した．結果は理論の予想どおりにCPP-MRがCIP-MR より大きいというものであった，しかし，超伝導端子を用 いているために，測定は低温，低磁場に限られてしまう。

CPP-MRの室温までの温度変化は，才ランダのフィ リップスのグループによって測定されだ），被らは，平面 基板上に作成された人工格子を微細加工技術を用いてミク ロンオーダーの断面積の柱上に加工することで，測定抵抗 
をm $\Omega$ オーダーにすることに成功した．（Fig.2(b)）しか し、この加工には高度な技術と高価な装置が必要である.

最近, ベルギーのグループがメンブレンフィルターの小 さな穴に電着法により作成した人工格子を用いてCPPMR測定の報告をした ${ }^{5)}$. (Fig.2(c)）この人工格子は， 直径が数百オングストロームで長さが数ミクロンの紐上を しているので, 形状的には最もCPP-MRの測定に向いて いると言える. また, このような試料はナノスケールの人 工格子細線とも言え, 巨大磁気抵抗効果以外にも面白い物 性を示す可能性が期待される. しかし, 電着法を用いてい るため, 利用できる物質の種類の制約, 組成变調の不完全 性, などの問題もある. 我々は, Fig.1(c)のような形状の 人工格子の巨大磁気抵抗効果を研究している ${ }^{6)}$. Fig.3に 示すように，このような形状の試料では, 微細加工された 溝と平行な電流による磁気抵抗効果はCIP-MRと考えられ る. 一方, 溝之垂直方向に流れる電流は人工格子膜面と一 定の角度をなしている，我々はこの配置をCAP(current at an agle to the plane)配置と呼んでいる.このような膜面 と一定角度を持つ電流による磁気抵抗効果の測定は, 従来 の平面基板上の試料では行うことができず，微細加工基板 上の人工格子特有の測定である. また，同一の試料でCIP とCAPという異なった配置での磁気抵抗効果の測定ができ ることも新しい点である。 さらに，測定は簡便な 4 端子法 で行うことができ，温度や磁場に対する制約もない，

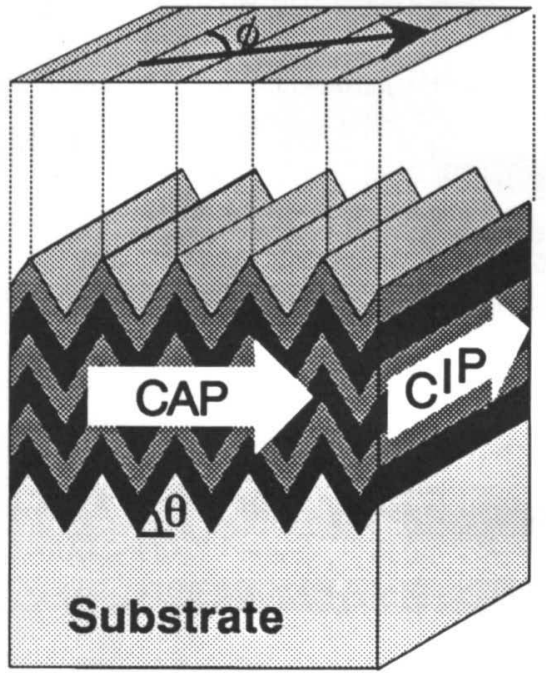

Fig.3 Schematic illustration of the configuration between current and multilayer plane. Current direction is indicated by arrow.

\section{2 実験方法}

$\mathrm{Si}(100)$ 基板上に異方性エッチングを用いてV字形の溝 を微細加工する方法は既に確立されている7). $\mathrm{Si}(100)$ 基 板上に $\mathrm{SiO}_{2}$ の熱酸化膜を $1500 \AA$ 程度成長させた後, レジス トを塗布する．このレジストを電子露光により $1 \mu \mathrm{m}$ 間隔 で0.1 $\mu \mathrm{m}$ の幅を持つストライプ上にパターニングする. $\mathrm{SiO}_{2}$ 層をHF水溶液でエッチングすることにより，ストラ イプ状の $\mathrm{SiO}_{2}$ 層ができる. これをマスクとして $\mathrm{KOH}$ 水溶 液でSiをエッチングする. (100)面のエッチング速度は (111)面よりはるかに大きいので, (111)面を側面とする $1 \mu \mathrm{m}$ 間隔のV字溝ができる.このようにして作成した基 板のSEM写真をPhoto.1に示す.

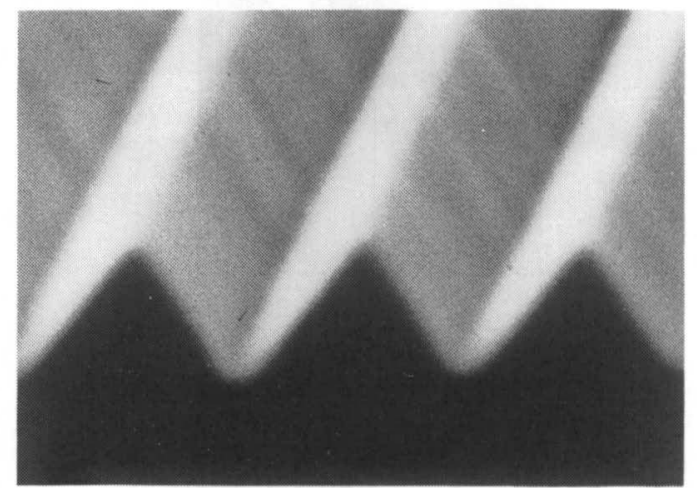

Photo.1 SEM image of V-grooved substrate prepared by anisotropic etching.

基板の形状をSEMで確認した後, 基板に対して垂直の方 向から蒸着して試料を作成する．基板は膜厚の分布を小さ くするために20rpm程度で回転させる. 今回作成した人工 格子の組成は, $\mathrm{Co}(12 \AA) / \mathrm{Cu}(\mathrm{X} \AA) / \mathrm{NiFe}(12 \AA) / \mathrm{Cu}(\mathrm{X} \AA)$ $\mathrm{X}=58,116,174,232 \AA$ であり, 総膜厚は基板に垂直な 方向に $4 \mu \mathrm{m}$ で一定としている. 総膜厚 $4 \mu \mathrm{m}$ はV 字溝の 幅 $1 \mu \mathrm{m}$ より十分大きいと考えられるので，伝導性の議論 においてはFig.3の概念図に示される人工格子の上下の三 角プリズム状の部分は無視できる.つまり，溝に垂直に流 れる電流は人工格子膜面と $54.7^{\circ}$ の角度を持つと考えられ る.このような試料で磁場を掃引していくと， Coと NiFe の保磁力の違いのために，Co層の磁化とNiFe層の磁化が 反平行になる磁場領域が存在する. 磁化が反平行配置をと る磁場領域で電気抵抗は大きくなる。このように保磁力の 差を利用して磁化の反平行配置を作りだす非結合型の人工 格子は，磁性層間相互作用によって反平行配置が実現され る $\mathrm{Fe} / \mathrm{Cr} や \mathrm{Co} / \mathrm{Cu}$ 人工格子に比へてて，いくつかのメリット がある ${ }^{8)}$. まず, 小さな印加磁場でかなり大きな磁気抵抗 
変化率が得られるので, 磁気ヘッドへの応用に向いている. また，層間相互作用を利用する結合型人工格子では，磁性 層間に反強磁性的な相互作用が存在する限られた非磁性層 の厚さでしか巨大磁気抵抗変化が得られないが, 非結合型 では，磁性層間相互作用が無視できる厚さであれば，必ず 巨大磁気抵抗変化が得られる.このため, 磁気抵抗変化率 の非磁性層厚依存性が容易に研究できる. Fig.3に示すよ うな試料では, 溝と電流間の角度を $\phi$ とした場合, 電気抵 抗の $\phi$ 依存性も測定できる. $\phi=0^{\circ}$ がCIPに， $\phi=90^{\circ}$ がCAPに対応する.

試料の構造観察はSEMを用い, 磁化測定はVSM, SQIUDを使用した．磁気抵抗の測定は 4 端子法で $2 \mathrm{~K}$ から 300Kの温度範囲で行った，磁化測定, 磁気抵抗測定は, 磁場を膜面ないで微細加工の溝と平行に印加して行った。

\section{3 実験結果および考察}

作成された試料のSEM写真をPhoto.2とPhoto.3に示す. Photo.2は試料上部の写真である. Photo.1の微細加工基板 の写真と比へると，4ミクロンの人工格子を作成しても基 板の形状か膜の表面まで保たれていることがわかる.

Photo.3は試料断面の像である. 膜の上下の三角プリズム 状の部分は膜全体に比へてその割合は小さい。そのため CAP配置での伝導性に関してはこの部分を無視することに する. この研究で用いられた試料の室温での典型的な磁化 曲線をFig.4に示す. 試料の組成は, $[\mathrm{Co}(12 \AA) / \mathrm{Cu}(116 \AA)$ $/ \mathrm{NiFe}(12 \AA) / \mathrm{Cu}(116 \AA)]^{*} 91$ である、この磁化曲線は階段状 をしており，磁化の反平行配置が実現していることを示し ている.つまり、高磁場領域ではコバルトとパーマロイの 磁化は平行配置をとり、磁化曲線が階段状を示すコバル卜 とパーマロイの保磁力間の磁場領域で、これらの磁化は反 平行になっている. 同じ試料の室温での磁気抵抗曲線を Fig.5に示す. Fig.4でコバルトとパーマロイの磁化が反平

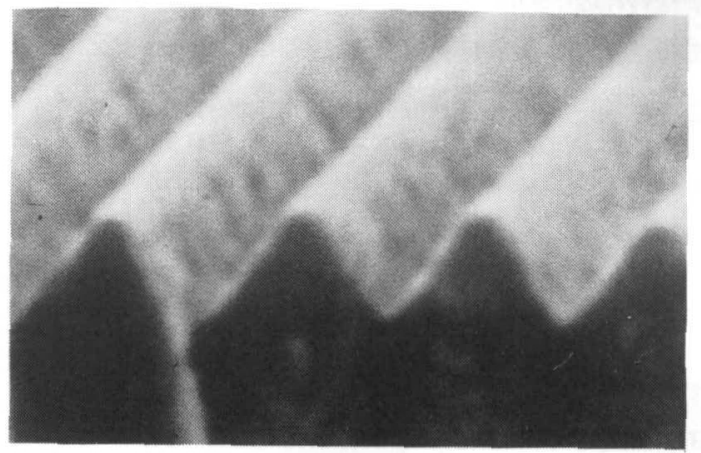

Photo.2 SEM image of multilayer suface prepared on Vshaped substrate.

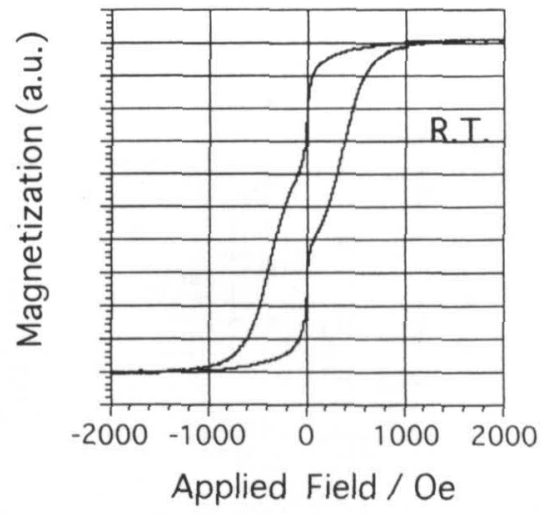

Fig.4 Magnetization curve at R.T. for the sample $[\mathrm{Co}(12 \AA) / \mathrm{Cu}(116 \AA) / \mathrm{NiFe}(12 \AA) / \mathrm{Cu}(116 \AA)]^{* 91}$. Magnetic field was applied parallel to the grooves in multilayer plane.

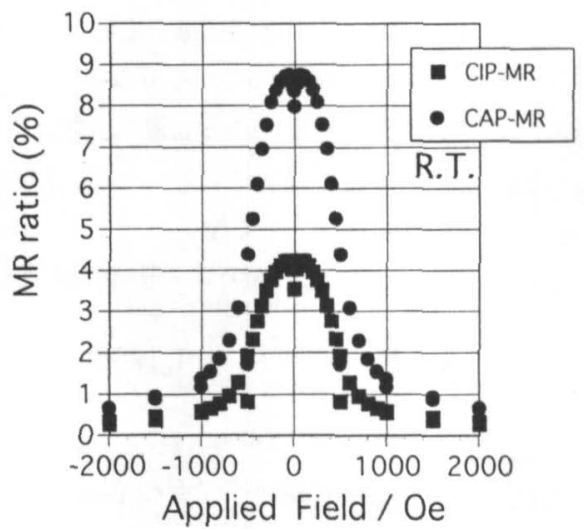

Fig.5 MR curve at R.T. for the sample $[\mathrm{Co}(12 \AA) / \mathrm{Cu}(116 \AA) / \mathrm{NiFe}(12 \AA) / \mathrm{Cu}(116 \AA)]^{* 91}$. Magnetic field was applied parallel to the grooves in multilayer plane.

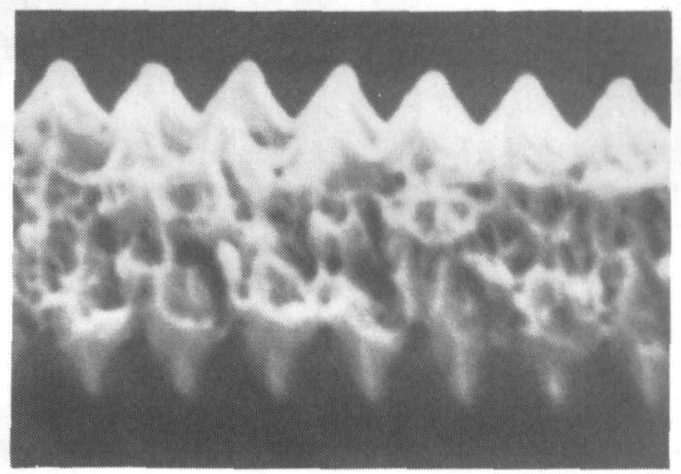

Photo.3 Cross sectional SEM image of multilayer prepared on V-shaped substrate. 


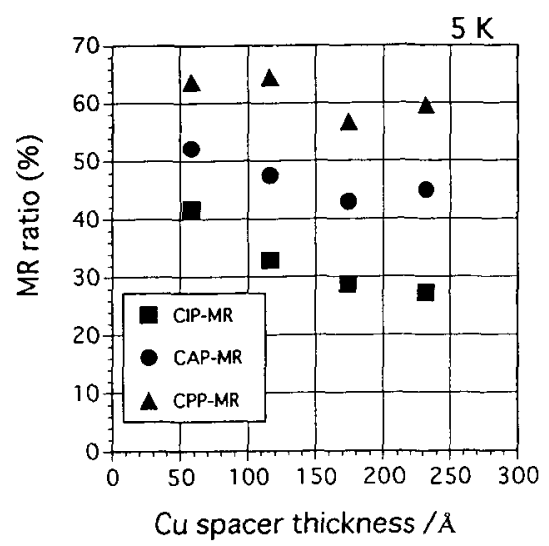

Fig.6 MR dependence on Cu spacer thickness of CIP-MR, CAP-MR and estimated CPP-MR at 5K.

行になっていると考えられる磁場領域で電気抵抗は增大し ている. CAP-MRはCIP-MRに比へててかなり大きくなっ ている.このことはCAP配置の方が伝導電子がより多くの 界面をよぎためであると考えられる.

LevyらはCIPの伝導率 $\sigma_{\mathrm{CPP}}$, CAPの伝導率 $\sigma_{\mathrm{CAP}}, \mathrm{CPP}$ の伝導率 $\sigma_{\mathrm{CPP}}$ の関保式として次の式を導いた。

$$
\sigma_{C A P}=\sigma_{C I P} \cos ^{2} \theta+\sigma_{C P P} \sin ^{2} \theta
$$

ここで $\sigma_{\mathrm{CP}}$ と $\sigma_{\mathrm{CAP}}$ は実験から求められる. したがって， この式を用いて $\sigma_{\mathrm{CPP}}$ が得られるので，CPP-MRの值を見 積ることができる。

Fig.6に磁気抵抗変化率のCu層厚依存性を示す．測定温

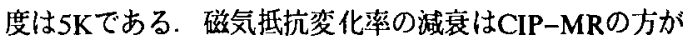
CPP-MRよりはるかにはげしい，理論的には，CIPMRが電子の平均自由行程により規定されるのに対し。 CPP-MRはスピン搪散距㜠に支配されると言われている. 低温では，スピン拡散距離は数ミクロンにもおよふ，一方， 平均自由行程は数百オングストローム程度と考えれる. 実 験された数百オングストロームの非磁性層厚の範囲で， CPP-MRはほとんど一定であるがCIP-MRは減衰してい くという我々の実験結果は、このような考え方を支持して いる.このように厚い非磁性層に対しても反平行な磁化配 置を得られるということが、非結合型人工格子の大きな利 点である。

磁気抵抗変化率の $\phi$ 依存性をFig.7に示す、試料の組成 は, $[\mathrm{Co}(12 \AA) / \mathrm{Cu}(58 \AA) / \mathrm{NiFe}(12 \AA) / \mathrm{Cu}(58 \AA))]^{*} 167$ であり， 測定温度は5Kである。実線は理論式による計算結果であ り，実験値をよく再現している。

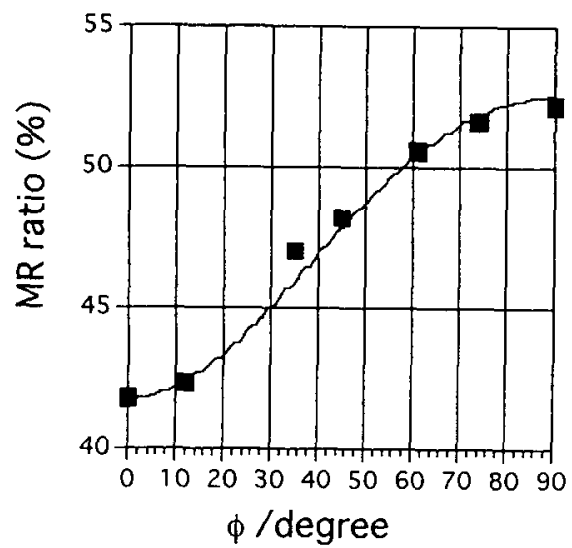

Fig.7 MR dependence on the angle $\phi$ between current and groove atr $5 \mathrm{~K}$. This configuration is illustrated in Fig.3. The solid line is the calculation result.

\section{4 まとめ}

微細加工基板上に非結合型人工格子を作成し，巨大磁気 抵抗効果について研究した，微細加工基板上の人工格子を 用いることにより，電流之人工格子膜面の関䋆加ら見て新 しい配置での磁気抵抗効果(CAP-MR)の測定が可能となっ た．CAP-MRはCIP-MRより大きく，応用の面からも期 待が持てる，測定されたCIP-MRとCAP-MRの值を用い てCPP-MRの値を見積ることが出来る。この方法は，こ れまで報告されたCPP-MRの測定法に比へて，試料作成 と測定が容易であるという利点がある．微細加工基板状の 人工格子は，新たな構造の付加された人工格子と見ること が出来，この特徽が生かされた新しい物性の発現が期待さ れる。

\section{愔辞}

試料作成にあたって，山本英文氏，杉田康成氏に協力し て頂きました. Prof. P.M. Levy, Dr. S. Zhang, 壬生攻氏 練系信好氏には有益な議論をして頂きました。

微細加工用のSi基板は，NECとHITACHIから頂きまし た

\section{文献}

1) M.N.Baibich, J.M.Broto, A.Fert, F.Nguyen Van Dau, F.Petroff, P.Etienne, G.Creuzet, A.Friederich and J.Chazelas: Phys.Rev.Letl.61(1988)2472.

2) S.Zhang and P.M.Levy: J.Appl.Phys.69(1991)4786.

3 ) W.P.Pratt.Jr., S.F.Lee, J.M.Slaughter, R.Loloee, 
P.A.Schroeder and J.Bass: Phys.Rev.Let1.66(1991)3060.

4) M.A.Gijs, S.K.J.Lenczowski and J.B.Giesberg: Phys.Rev.Lett.70(1993)3343.

5 ) L.Piraux, J.M.George, J.F.Despres, C.Leroy, E.Ferain, R.Legras, K.Ounadjela and A.Fert: Appl.Phys.Lett.65(1994)2484.

6) T.Ono and T.Shinjo: J.Phys.Soc.Jpn.64(1995)363.

7) E.Bassous: IEEE Trans.ED25(1978)1178

8) T.Shinjo and H.Yamamoto:
J.Phys.Soc.Jpn.59(1990)3061.

巨大磁気抵抗効果の解説としては次の文献があげられる.

9）長谷川秀夫: 日本応用物理学会誌, 15(1991)806.

10）井上順一郎，前川禎道: 日本応用物理学会誌，16 (1992)623.

11 ）新庄輝也: 応用物理, 61(1992)1214.

12 ）高梨弘媇，藤森啓安: 固体物理，28(1993)637.

13 ）猪俣浩一郎: 応用物理, 63(1994)1198. 